\title{
SPATIO TEMPORAL CHANGE OF SELECTED GLACIERS ALONG KARAKORAM HIGHWAY FROM 1994-2017 USING REMOTE SENSING AND GIS TECHNIQUES
}

\author{
Yasmeen Anwar ${ }^{1}$, Javed Iqbal ${ }^{2}$ \\ 1 National University of Sciences and Technology (NUST), Pakistan (yanwar.ms15igis@igis.nust.edu.pk) \\ ${ }^{2}$ National University of Science and Technology (NUST), Pakistan
}

KEY WORDS: Global warming, Glaciers, Karakoram Range, Change Detection, Floods, GIS \& RS, Supervised classification

\begin{abstract}
:
With the acceleration of global warming glaciers are receding rapidly. Monitoring of glaciers are important because they caused outburst of floods the past. This research delivers a systematic approach for the assessment of glaciers i.e. Batura, Passu, Ghulkin and Gulmit cover along the Karakoram Highway. Main reason to select these glaciers was their closeness to Karakoram Highway which plays an important role in China-Pakistan economic corridor (CPEC). This study incorporates the techniques of Geographical Information System and Remote Sensing (GIS \& RS). For this study, Landsat 4,5,7,8 images were taken for the years of 1994, 2002, 2009, 2013 and 2017. Using the said images supervised classification was done in ArcMap 10.3 version to identify the changes in glaciers. The area was categorized into six major classes' i.e. Fresh snow, Glaciers, Debris, Vegetation, Water bodies and Open land. Classified results showed a decrease in the area of Glaciers, almost 3.5\% from 1994 to 2017. GLIMS data about boundary of glaciers of 1999 and 2007 was compared with the classified results which show decrease in terminus of glaciers. Batura glacier has been receded almost $0.6 \mathrm{~km}$ from 1999 to 2017, whereas Passu glaciers receded $0.3 \mathrm{~km}$, whereas Gulmit and Ghulkin glaciers are more stable than Passu and Batura with the difference of -0.05 and $+0.57 \mathrm{~km}$ respectively. At the end results from classified maps were compared with the climatic data. Wherein temperature is rapidly increasing resulting in melting of glaciers and can cause shrinkage of fresh water as well as destruction to Karakoram highway in case of outburst floods.
\end{abstract}

\section{INTRODUCTION}

Climate change is a global problem, which is causing melting of glaciers. Increased melt water can cause shrinkage of glacier mass, and is contributing towards increased downstream water flow. (James D. Miller, 2012) Pakistan is a south Asian country, which is located between $24^{\circ}-37^{\circ} \mathrm{N}$ latitude and $66^{\circ}-77^{\circ} \mathrm{E}$. Pakistan has the junction point of world's largest mountain ranges i.e. Himalaya, Karakoram and Hindukush (HKH) having largest glaciers besides the poles. These glaciers provide water to river system of Pakistan (Rasul G., 2015). Pakistan water resources depend on glacier melted water from $\mathrm{HKH}$ ranges. Melted water is used for domestic purpose, agriculture, generating the electricity etc. Melted water of Himalayas and Karakoram glaciers provide discharge to Indus basin and its tributaries.

As the climate changes, glaciers are melting with swiftness. Because of this, community of that region faces hazards like floods, land sliding, avalanches etc. GLOF is the major threat to that region, because glaciers are melting with the rate of 40-60 meters per decade in Pakistan and causing a massive increase in glacier lakes. In the formation of GLOF $\mathrm{v}$-shaped valleys can change in a colossal destruction. In Pakistan there are 5218 glaciers and 2420 lakes present, in which 52 lakes are categorized as risky. (Rasul G., 2015)

Like all over the world's glaciers, Himalayan glaciers are also decreasing. Karakoram glaciers were also shrinking in past 19201990 except for some short term advances in 1970's. After 1990 many Karakoram glaciers began to increase. In between 19972002, 13 glaciers were noticed as expanding. (Hewit, 2005)
Although Himalayans glaciers are receding day by day, Karakoram glaciers are behaving oppositely. It is observed that Karakoram glaciers are surging from 1860s and in recent years glaciers are surging with high rate. Rapid advance in glacier tongue caused by surge invokes the danger of glacier lake outburst flood (GLOF), 35 GLOFs are reported since 1826 in Karakorum region (M. Rankl, 2013).

Mapping glaciers is a key application of optical satellite data and has been widely used, particularly after the free availability of Landsat imagery. Glaciers outline monitoring is very important for any calculation and modeling regarding the glaciers. Classification of glaciers is based on solid change between snow and glaciers spectral reflectance (Frank Paul, 2016).

Remote Sensing and Geographical information system (GIS) related methods for monitoring the glaciers are very easy and time saver as compare to old methods. Classification of glaciers and GIS based methods for extraction of glaciers from Landsat data are exceedingly valuable and extensively distinguishable for glaciers mapping. There are many methods for glacier monitoring i.e. normalized difference snow index (NDSI), visual interpretation, and image classification techniques etc. (Slater 1999, A Shukla et.al, 2009).

This study focuses on spatiotemporal change in glacier mapping and change in the area of glacier lakes using the techniques of Remote Sensing and Geographical Information System. Main objectives to achieve the target are; 1) to map the spatiotemporal change of glaciers and area of glacier lakes. 2) To compare the glacier change with the climatic variable. 


\section{MATERIALS AND METHODS}

\subsection{Study Area}

Study area starts from Gulmit to Passu Sost, which comes in Upper Hunza-Gojal valley, almost $70.7 \mathrm{~km}$ distance on KKH. The study area includes four main glaciers which are Gulmit glacier, Passu glacier, Gulkin glacier and Batura glacier and three glacier lakes which Borith Lake, Passu Lake and newly formed lake near Tupopadan. Batura glacier is $57 \mathrm{~km}$ long, one of the longest glacier outside the polar region. It is situated in Gojal region of Pakistan. Coordinates of Batura glacier is $36^{\circ} 32^{\prime} \mathrm{N}$ 7430'E. Passu glacier lies beneath the Batura Glacier. Location of Passu glacier is $36.4667 \circ \mathrm{N} 74.7667^{\circ} \mathrm{E}$. Main areas of study area are Passu village, Hussaini village, Ghulkin and Gulmit village. The climate of Karakorum is influenced by Asian monsoon which cause $80 \%$ of precipitation of southeastern part of Karakoram region. Winger et.al recorded the precipitation values in Karakorum Range is 1600 to 1800 mmyr-1. Bolch et.al observed high amount of precipitation in Karakoram Range since the early 1960s.

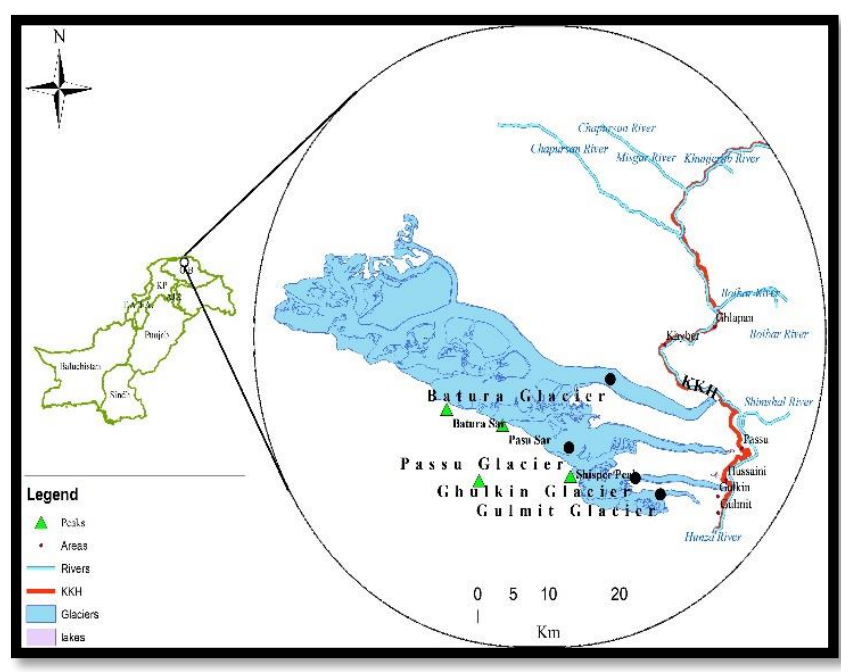

Figure 1: Study Area

\subsection{Dataset}

For this study we use Landsat images, for the years of 1994, 2002, 2009, 2013 and 2017 of summer period. Images were MSS, ETM+ and OLI. Global Land Ice Measurements from Space (GLIMS) data, boundary of glacier were acquired for comparison. Climate data was acquired from Pakistan Meteorological Department (PMD) and Water and Power Development Authority (WAPDA) of Khunjerab station and Hunza station from 1995-2013 and 2007-2017 respectively.

\begin{tabular}{|c|c|c|}
\hline Data & Year & $\begin{array}{c}\text { Resolution } \\
\text { (meters) }\end{array}$ \\
\hline Landsat 4-5 MSS & 1994 & 30 \\
\hline Landsat 4-5 MSS & 2002 & 30 \\
\hline Landsat 7 ETM+ & 2009 & 30 \\
\hline Landsat 8 OLI & 2013 & 30 \\
\hline Landsat 8 OLI & 2017 & 30 \\
\hline
\end{tabular}

Table 1: Data acquisition of remotely sensed imagery

\subsection{Methodology}

The thorough methodology is illustrated in Figure 2, in which main steps are image preprocessing, extraction of study area, supervised classification and change detection mapping. Landsat images were taken for the years of 1994, 2002, 2009, 2013 and 2017 i.e. ETM, MSS+ and OLI. For image preprocessing Erdas Imagine version 14 were used, image preprocessing enhance the image quality which helps in analysis.

Staking was also done in Erdas imagine, subset the study area from staked images. For supervised classification ArcMap 10.3 was used. Training samples were collected with the help of google earth and by visual interpretation.

Accuracy assessment, of classified images were done in ArcMap 10.5 version, by ratio of sums of diagonal values and total number of assessed pixels/values and the resultant is the correctly classified pixels given in percentage (Campbell and Wyne. 2011). The percentage hange in glaciers was calculated using the following formula.

Percentage Change in Glacier Cover $=[(\mathrm{y}-\mathrm{x}) / \mathrm{z}] * 100$ (Eq. 1)

Where,

$\mathrm{x}=$ glacier area in old year

$\mathrm{y}=$ glacier area in current year

$\mathrm{z}=$ total area

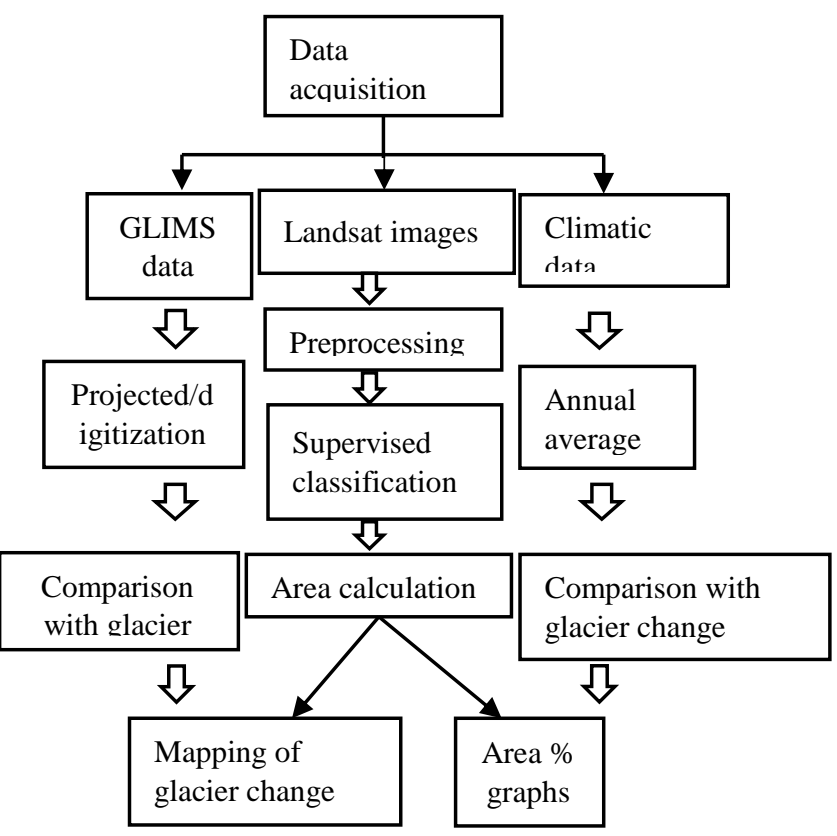

Figure 2: Methodology for mapping temporal change of glaciers. 

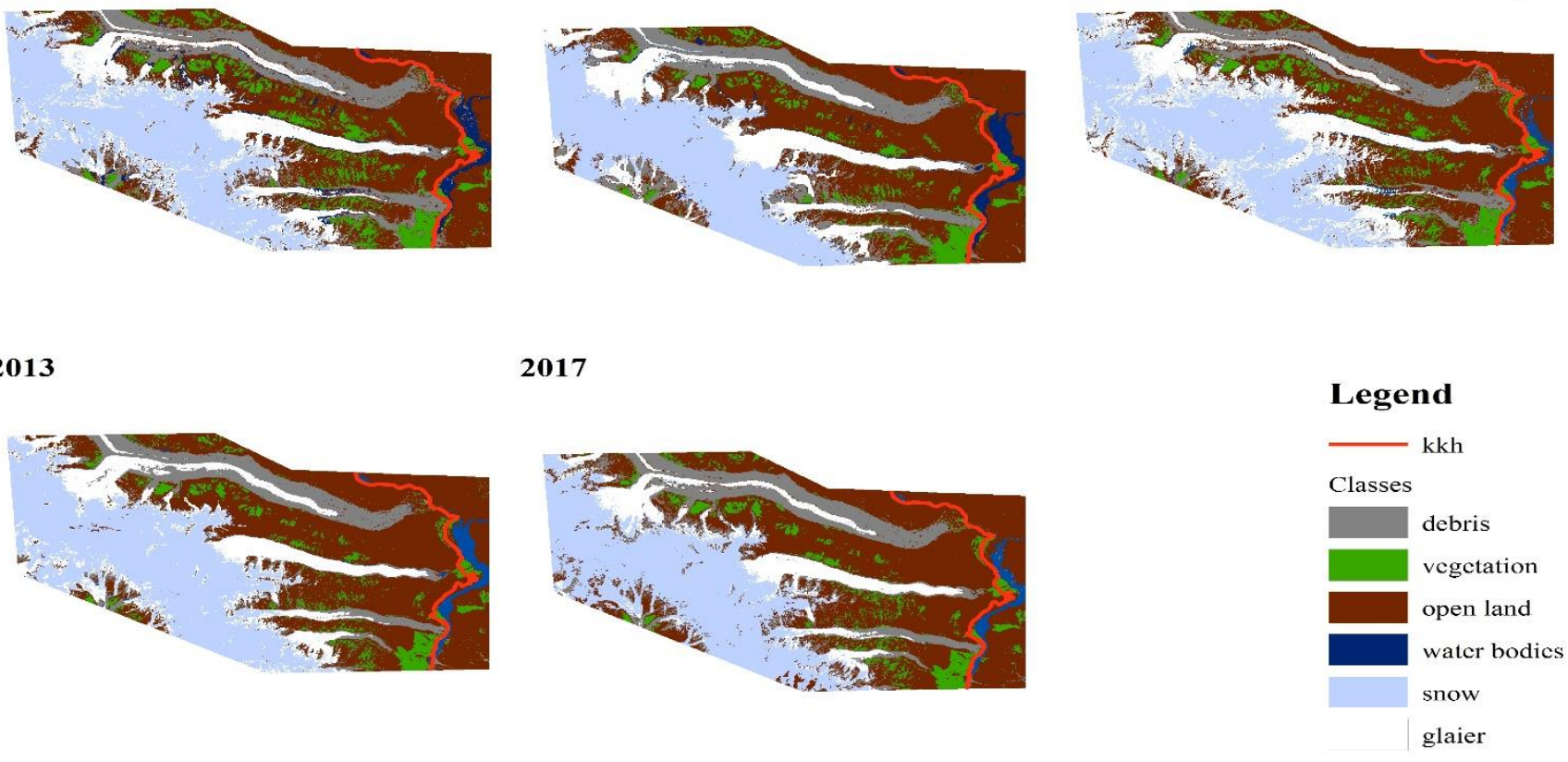

Figure 3: Spatiotemporal change of Glacier (1994-2017)

\section{RESULTS AND DISCUSSIONS}

\subsection{Classification and Glacier Cover Change Maps}

This study focuses on the spatiotemporal change of glaciers. Figure: 3 is showing the classified map of study area from 1994 to 2017. Results of Landsat 8 are clearer than Landsat 4/5, because glaciers can be easily identify in more spectral bands. High number of bands can easily identify snow, ice and debris to 2017.

Results of Landsat 8 are clearer than Landsat $4 / 5$, because glaciers can be easily identified in more spectral bands. High number of bands can easily identify snow, ice and debris. Glaciers classification is usually done in spectral bands (Paul et al., 2016). It is difficult to identify the boundary of glaciers with less bands. Different studies illustrate that Karakoram glaciers are behaving anomalously and surging (Gardelle 2012). Temporal analysis were performed on Landsat images, four glaciers (Batura, Passu, Gulmit and Ghulkin) were taken for this study. Classified maps have main six classes i.e. Fresh snow, Debris, Glaciers, water bodies (rivers, lakes), Open land (mountains) and Vegetation (shrubs, trees, grass etc.). Accuracy of classified images was assessed in ArcMap 10.5 version. Overall accuracy of 1994, 2002, 2009, 2013 and 2017 images was $79 \%, 80 \%, 74 \%, 82 \%$ and $85 \%$ respectively.

The change in percentage in each class is represented in bar graph in Figure 4. Result showed the change in area of glaciers (glacier and debris) i.e. 3.53\% decrease from 1994 to 2017.
As the study focuses on Glacier change, comparison with GLIMS data was also done in this study.

Terminus points of glaciers were compared with GLIMS boundary data. Terminus of Batura glaciers is changing with the passage of time. Figure 5 is showing the terminus of Batura Glacier of 1999, 2007 and 2017. Batura glacier is decreasing in length and stable in its width. From 1999 to 2017 the maximum decrease in length was recorded almost $0.6 \mathrm{~km}$ and it caused a slight increase in mass of newly formed lake at the terminus of Batura glacier.

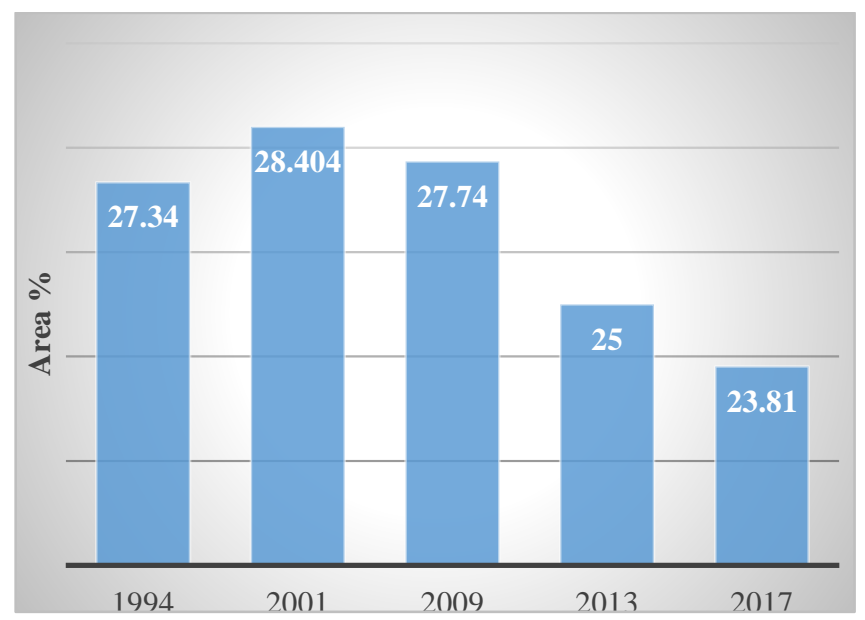

Figure 4: Glacier Area in percentage 

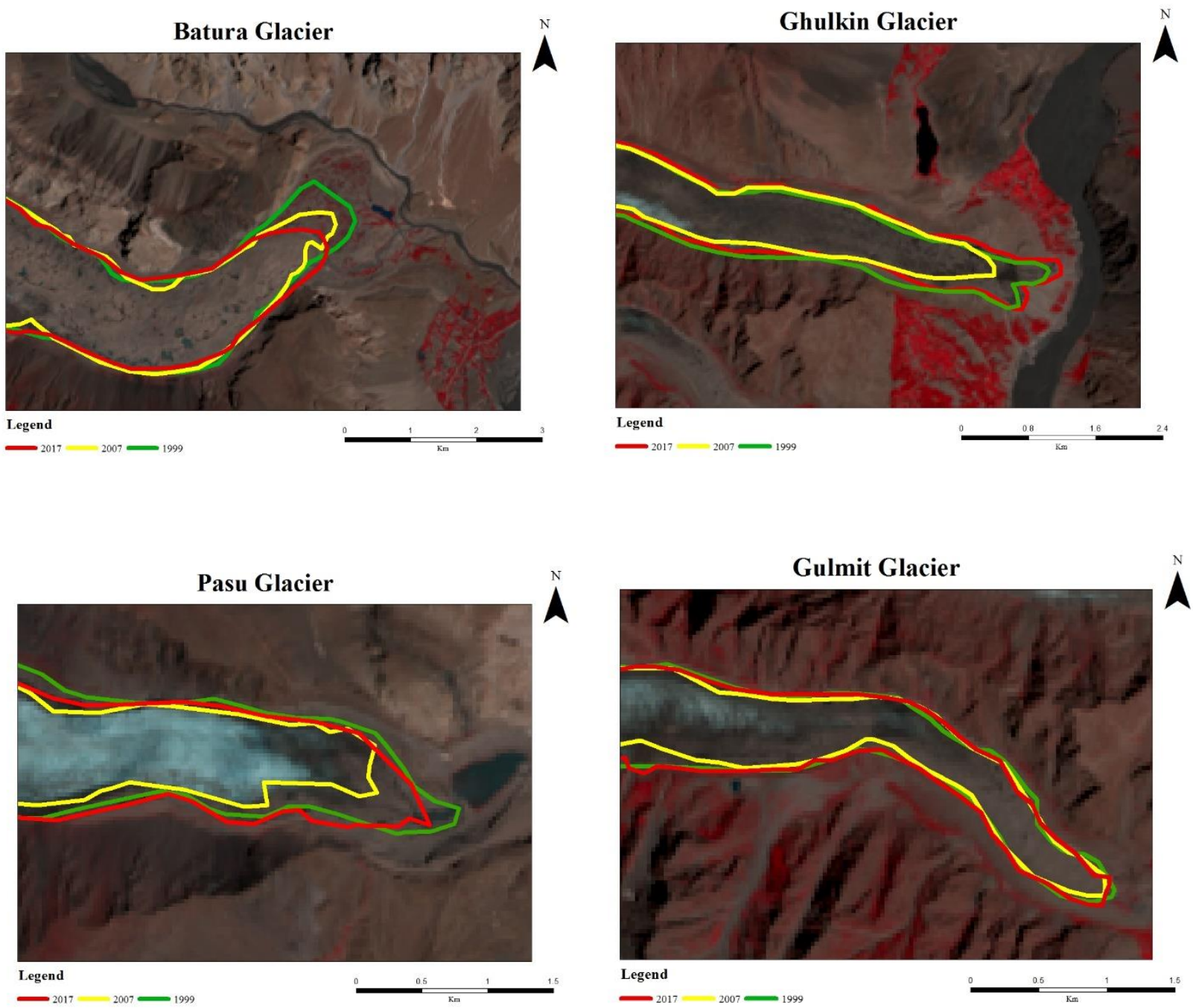

Figure 5: Terminus of glaciers

Situation of Passu glacier is not symmetric, in 1999-2007 the terminus was receded almost $0.75 \mathrm{~km}$ which increased in 2017 to $0.64 \mathrm{~km}$, so the difference from $1999-2017$ of terminus is $0.3 \mathrm{~km}$. The decrease in terminus also caused an increase in area of Passu Lake, formed in bottom of Passu glacier. There is a slight decrease in Ghulkin, Gulmit glacier's terminus. They are stable than the Passu and ra Glaciers. Differences in terminus of Ghulkin glacier is $0.157 \mathrm{~km}$ and of Gulmit glacier is $0.05 \mathrm{~km}$.

\subsection{Comparison with climatic data}

Climatic data (precipitation, temperature) was acquired from Pakistan Meteorological Department and Water and Power Development Authority of two station i.e. Hunza and Khunjerab respectively. Data of Hunza station was from 2007 to October, 2017 and data of Khunjerab station was from 1995 to 2013. Graphical representation of climatic data is represented in Figure: 6 which is showing an increase in temperature of Hunza region and decrease in precipitation. The annual average temperature in 2007 was almost $1{ }^{\circ} \mathrm{C}$ whereas in 2017 the temperature was almost $14{ }^{\circ} \mathrm{C}$, the change in temperature is enormous. Pattern of Precipitation of Hunza region seems to be changed in this period. Annual average precipitation in 2007 was almost $1 \mathrm{~mm}$ but decreased in 2017 to the level of $0.22 \mathrm{~mm}$.

Khunjerab station is situated at higher altitude than Hunza station therefor Hunza station results are more relatable to study area than those of Khunjerab station. Results of Khunjerab station shown in Figure: 7 are showing the bar graph of annual average temperature (bars) and annual average precipitation data (line). Climatic situation is not symmetric in Khunjerab region as in Hunza region. Temperature and precipitation is not static but have ups and downs. Temperature is in negative because of high altitude, in 1995 temperature was $-0.6^{\circ} \mathrm{C}$ and in 2013 it was increased at the value of almost $-0.4{ }^{\circ} \mathrm{C}$, on the other side precipitation is a bit increased from $0.22 \mathrm{~mm}$ to $0.49 \mathrm{~mm}$. Temperature is increasing and precipitation is decreasing rapidly because of global climate change.

Chaudhary et.al 2009 stated in his study that Pakistan experienced $0.76^{\circ} \mathrm{C}$ rise in temperature in last 40 years. However, mountainous area which is the place of number of glaciers has experienced a rise in temperature of $1.5^{\circ} \mathrm{C}$. Precipitation at $4000 \mathrm{~m}$ altitude, where precipitation used to be very common, has decreased. They also stated that persistency of heat waves in glacier region is causing melting of glaciers and 
outburst of terminus lakes. Projected temperature was $0.6^{\circ} \mathrm{C}$ for Pakistan for 2001-2010 which was recorded $0.93^{\circ} \mathrm{C}$ and northern region heated up to the $1.3{ }^{\circ} \mathrm{C}$, which is a frightening indicator for outburst flooding of glacier lakes.

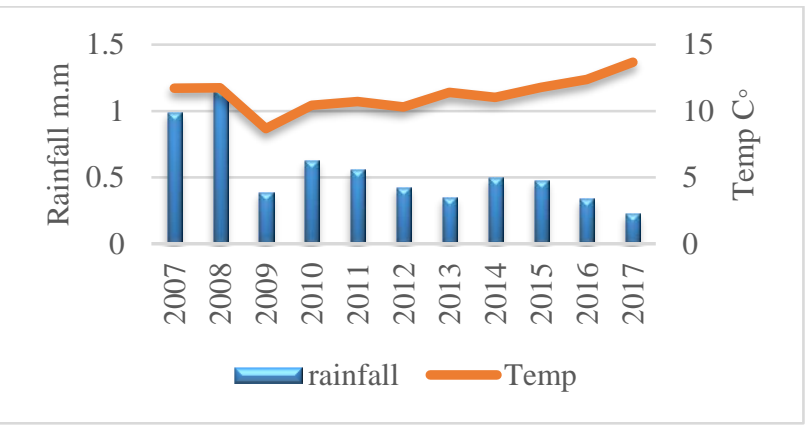

Figure 6: Hunza Station

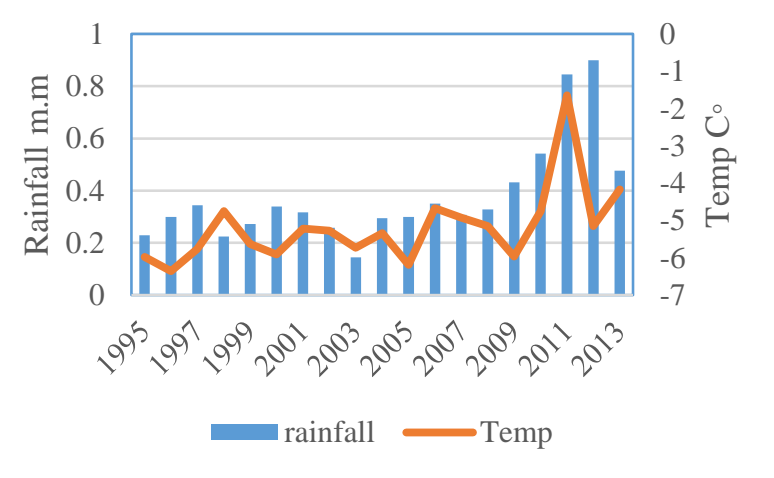

Figure 7: Khunjerab Station

\section{CONCLUSION}

Monitoring of glacier change is very important because of global climate change. This study was focused on mapping of spatiotemporal change of glaciers and related lakes. For mapping remote sensing and geographical information system techniques were used because these techniques are time saver, more accurate and have access to remote areas. Supervised classification was done on Landsat imageries, to identify the change in area of glaciers. Results from supervised classification identifies that $3.53 \%$ of glacier area of Batura, Passu, Ghulkin and Gulmit glacier has been decreased since 1994 to 2017. Delineated boundary of discussed glaciers, from the results, was then compared with GLIMS boundary of glaciers that showed receding of terminus of Batura, Passu, Ghulkin and Gulmit glacier $0.75,0.3,0.157$ and $0.05 \mathrm{~km}$ respectively.

In last results were compared with the climatic variable i.e. temperature and precipitation. Climate data of Khunjerab and Hunza station of years 1995-2013 and 2007-2017, showed an increase in annual average temperature from $1{ }^{\circ} \mathrm{C}$ to $14{ }^{\circ} \mathrm{C}$ and $0.6^{\circ} \mathrm{c}$ to $-0.4^{\circ} \mathrm{c}$ respectively. It showed rise in temperature and diminution in precipitation which led to the conclusion that because of the rise in temperature caused by global warming, glaciers are receding. Decrement in the area of glaciers is an alarming threat to freshwater bodies caused by the global warming.

\section{ACKNOWLEDGEMENTS}

This work was performed under the supervision of Dr Javed Iqbal, HOD Institute of Geographic Information System (IGIS), NUST Pakistan. The research was funded by NUST HQ. This study acknowledges contributions from the Pakistan Meteorological Department (PMD) and Water and Power Development Authority (WAPDA) for the provision of data. The views enunciated here are solely of the author and are not necessarily reflection of the above-mentioned organizations.

\section{REFERENCES}

Ashraf, A., Roohi, R. and Naz, R., 2011. Identification of glacial flood hazards in karakorum range using remote sensing technique and risk analysis. Science Vision, 16, pp.71-80.

Hewitt, K., 2005. The Karakoram anomaly? Glacier expansion and the 'elevation effect,'Karakoram Himalaya. Mountain Research and Development, 25(4), pp.332-340.

Man, Q.X., Guo, H.D., Liu, G. and Dong, P.L., 2014. Comparison of different methods for monitoring glacier changes observed by Landsat images. In IOP Conference Series: Earth and Environmental Science (Vol. 17, No. 1, p. 012127). IOP Publishing.

Miller, J.D., Immerzeel, W.W. and Rees, G., 2012. Climate Change Impacts on Glacier Hydrology and River Discharge in the Hindu Kush-Himalayas: A Synthesis of the Scientific Basis. Mountain Research and Development, 32(4), pp.461-467.

Paul, F., Winsvold, S.H., Kääb, A., Nagler, T. and Schwaizer, G., 2016. Glacier Remote Sensing Using Sentinel-2. Part II: Mapping Glacier Extents and Surface Facies, and Comparison to Landsat 8. Remote Sensing, 8(7), p.575.

Rasul, G., Chaudhry, Q.Z., Mahmood, A., Hyder, K.W. and Dahe, Q., 2011. Glaciers and glacial lakes under changing climate in Pakistan. Pakistan Journal of Meteorology, 8(15).

Shukla, A., Gupta, R.P. and Arora, M.K., 2009. Estimation of debris cover and its temporal variation using optical satellite sensor data: a case study in Chenab basin, Himalaya. Journal of Glaciology, 55(191), pp.444-452. 